\title{
Erratum
}

Yoshie Souma*

\section{Erratum to: Efforts to improve Japanese women's status in STEM fields}

https://doi.org/10.1515/pac-2019-0601

Erratum to: Yoshie Souma. 2019. Efforts to improve Japanese women's status in STEM fields. Pure and Applied Chemistry. Volume 91, Issue 4, pages 733-741. (10.1515/pac-2018-0903):

Equations (1) and (2) of the article, "Efforts to improve Japanese women's status in STEM fields" [1], published in Pure and Applied Chemistry 91(4), April 2019, were incorrectly published in the printed version.

The correct equations should read as follows,

$$
\begin{gathered}
\mathrm{Cu}^{+}+(\mathrm{n}+1) \mathrm{CO} \rightarrow \mathrm{Cu}(\mathrm{CO})^{+}+\mathrm{Cu}(\mathrm{CO})_{\mathrm{n}}^{+} \mathrm{n}=2,3,4 \\
\mathrm{Ag}^{+}+2 \mathrm{CO} \rightarrow \mathrm{Ag}(\mathrm{CO})_{2}^{+}
\end{gathered}
$$

\section{Reference}

[1] Y. Souma, Pure Appl. Chem. 91, 733 (2018).

Article note: Erratum to a previously published Conference Paper.

*Corresponding author: Yoshie Souma, Emeritus Researcher at National Institute of Advanced Industrial Science and Technology, 1-9-15, Minamikasugaoka, Ibaraki, Osaka 567-0046, Japan, e-mail: y-souma@kce.biglobe.ne.jp 